\title{
TECNOLOGÍAS ECONÓMICAS PARA LA DESINFECCIÓN Y DESCONTAMINACIÓN DE AGUA, AVANCES EN ARGENTINA
}

\section{ECONOMIC TECHNOLOGIES FOR WATER DISINFECTION AND DECONTAMINATION, ADVANCES IN ARGENTINA}

\author{
Christian Navntoft ${ }^{1}$, Paula Araujo ${ }^{2}$, Cecilia Mendive ${ }^{3}$, Daniel S. Cicerone ${ }^{4}$, R. Pizarro ${ }^{5}$, \\ Galo Soler-Illia ${ }^{6}$, Laura Dawidowski ${ }^{7}$, Marta I. Litter ${ }^{8}$, Miguel A. Blesa ${ }^{9}$, \\ María C. Apella ${ }^{10}$, Margarita del V. Hidalgo ${ }^{11}$, María G. García ${ }^{12}$, \\ Priscilla Powell ${ }^{13}$, María Puchulu ${ }^{14}$, D. Fernández ${ }^{15}$.
}

\begin{abstract}
RESUMEN
El agua es un fluido de proceso de mucha importancia en Tecnología Nuclear. La Unidad de Actividad Química (UAQ) ha dedicado mucho esfuerzo al estudio de sus propiedades fundamentales y de sus aplicaciones, con miras a optimizar el funcionamiento de los sistemas refrigerante, moderador y auxiliares en Centrales Nucleares. Uno de los aspectos fundamentales de estudio ha sido la necesidad de mantener agua muy pura en esos circuitos, para minimizar la corrosión de los materiales estructurales, y la incorporación de radionucleídos al agua. Esta incorporación es responsable de un incremento de las dosis ocupacionales de radiación de los trabajadores. La tecnología del agua como insumo de la industria nuclear requiere poseer capacidades en la producción y mantenimiento de agua extremadamente limpia. Dichas capacidades son las que se usan también para brindar soluciones a la provisión de agua a comunidades rurales aisladas, y a las pequeñas empresas para encontrar alternativas al tratamiento de sus efluentes. Los estudios para estos fines se han canalizado a través de una colaboración con las Universidades Nacionales de San Martín y de Tucumán.
\end{abstract}

Palabras clave.- Agua, Industria nuclear.

\begin{abstract}
Water is a fluid process of great importance in Nuclear Technology. Chemical Activity Unit (UAQ) has devoted much effort to the study of fundamental properties and applications in order to optimize the operation of cooling systems, and auxiliary moderator in nuclear power plants. One of the fundamental aspects of this study was the need for very pure water in these circuits, to minimize corrosion of structural materials, and the incorporation of radionuclides into the water. This incorporation is responsible for increased radiation dose occupational workers. Water technology as an input of the nuclear industry, for skills, is required in the production and maintenance of water extremely clean. These capabilities are also used to provide solutions to the water supply to isolated rural communities, and small businesses to find alternatives to treat their effluents. Studies for this purpose have been channeled through a partnership with the National Universities of San Martín and Tucumán.
\end{abstract}

Keywords.- Water, Nuclear industry.

\footnotetext{
${ }^{1-15}$ Unidad de Actividad Química, Comisión Nacional de Energía Atómica, Escuela de Posgrado, Universidad Nacional de San Martín, Facultad de Ciencias Naturales e Instituto Miguel Lillo, Universidad Nacional de Tucumán, Argentina.
} 


\section{INTRODUCCIÓN}

\section{LA CONTAMINACIÓN DEL AGUA EN IBEROAMÉRICA}

Los tipos de contaminantes que han ido comprometiendo la calidad del agua de consumo humano, son según su orden de aparición:

Contaminación microbiológica.- Vibrio cholerae, Campilobacter jejuni, Escherichia coli patógenas, Salmonella, Shigella spp, Yersinia enterocolítica, adenovirus, virus de la hepatitis A, enterovirus, rotavirus, Cryposporidium spp. Estos son algunos de los organismos de mayor incidencia en enfermedades de transmisión hídrica.

Contaminación con metales.- Son conocidos episodios de contaminación aguda, como la contaminación con mercurio en aguas de la Bahía de Minamata en Japón, que causó decenas de muertes. En nuestra región, es preocupante la contaminación de la cuenca del Río Pilcomayo, debida a las explotaciones mineras en la región de Potosí. Especialmente destacada es la importancia del Hidroarsenicismo Crónico Regional Endémico (HACRE), que afecta vastas extensiones de Latinoamérica. La Figura 1 muestra, como ejemplo, los niveles que hemos medido de arsénico en aguas subterráneas de la Provincia de Tucumán, y describe los objetivos de la Red CYTED recientemente creada en torno al problema del arsénico en Iberoamérica. En zonas densamente pobladas, como Buenos Aires, la contaminación con metales proveniente de efluentes industriales se superpone a la contaminación con materia orgánica y microbiológica. La Figura 2 describe someramente los objetivos de un proyecto en curso sobre el Río Reconquista.

Contaminación con agroquímicos.- Es un serio problema en los acuíferos Epipuelche y Puelche, de la Pampa Húmeda Argentina. Los plaguicidas son muchas veces refractarios al tratamiento biológico (barros activos), y requieren de otros métodos de destrucción, en particular las tecnologías avanzadas de oxidación fotoquímica que se describen en este trabajo.

Contaminación con contaminantes traza.- Es un problema relativamente reciente, que causa preocupación especialmente en Europa y EE.UU. Se encuentra en etapa de estudio, centrada en el desarrollo y disponibilidad de métodos de medición a niveles de ppt. Un ejemplo, es el estudio en curso en la UAQ de la detección de nonilfenol polietoxilado, cuyos productos de degradación son tóxicos (disruptores endocrinos).

Los países centrales han podido ir enfrentando, y en buena medida resolviendo, cada uno de estos problemas antes que el siguiente se volviera crítico. En cambio, en los países en vías de desarrollo todas estas formas de contaminación continúan siendo un factor que afecta la calidad del agua para consumo humano y, por ende, la calidad de vida de la población. 


\section{CONTAMINACIÓN POR ARSENICO}

Red CYTED IBERO ARSEN

- Mapa de niveles de arsénico en Iberoamerica

- Red de laboratorios con capacidad de análisis y manual de técnicas

- Manual de tecnologías disponibles

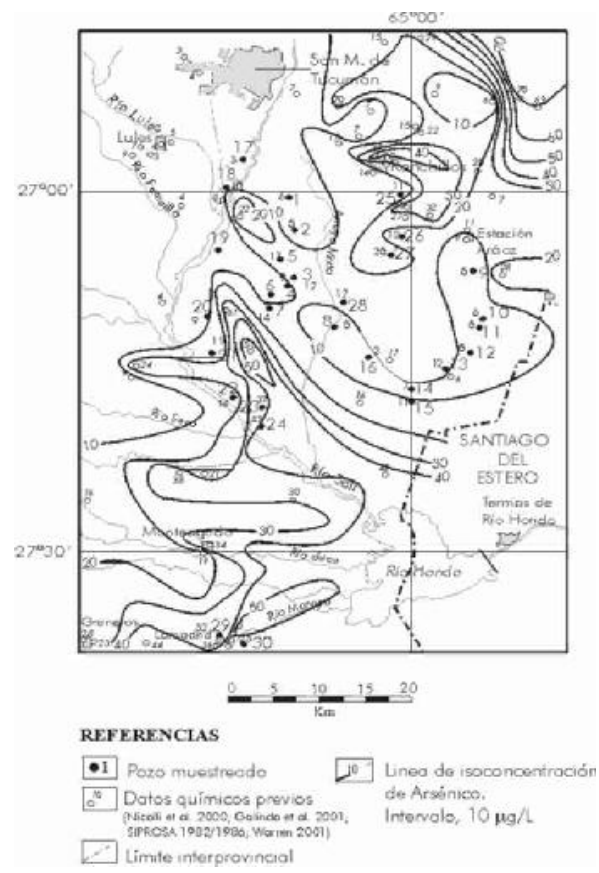

Fig. 1 Niveles de arsénico en aguas subterráneas de la Provincia de Tucumán, y los objetivos de la Red CYTED creada en torno al problema del arsénico en Iberoamérica

\begin{tabular}{l} 
CONTAMINACIÓN POR METALES PESADOS \\
$\begin{array}{l}\text { Proyecto integrado Universidad Nacional de San Martín } \\
\text {-volcados de } \\
\text { establecimientos } \\
\text { industriales y } \\
\text { descargas } \\
\text { cloacales } \\
\text { - modelado del río } \\
\text {-impacto de la } \\
\text { contaminación } \\
\text { sobre calidad de } \\
\text { vida } \\
\text { - transferencia }\end{array}-\begin{array}{l}\text { Campañas de } \\
\text { monitoreo de } \\
\text { agua y } \\
\text { sedimento. } \\
\text { Medición de } \\
\text { par ámetros } \\
\text { fisicoquímicos } \\
\text { in situ y en } \\
\text { laboratorio, } \\
\text { incluyendo } \\
\text { metales } \\
\text { pesados }\end{array}$ \\
\hline
\end{tabular}

Fig. 2 Objetivos de un proyecto en curso sobre el Río Reconquista.

\section{LA RADIACIÓN SOLAR EN IBEROAMÉRICA}

La Figura 3 da alguna información básica sobre la radiación solar, y la Figura 4 muestra los diversos fenómenos a través de los cuales es atenuada por la atmósfera. 


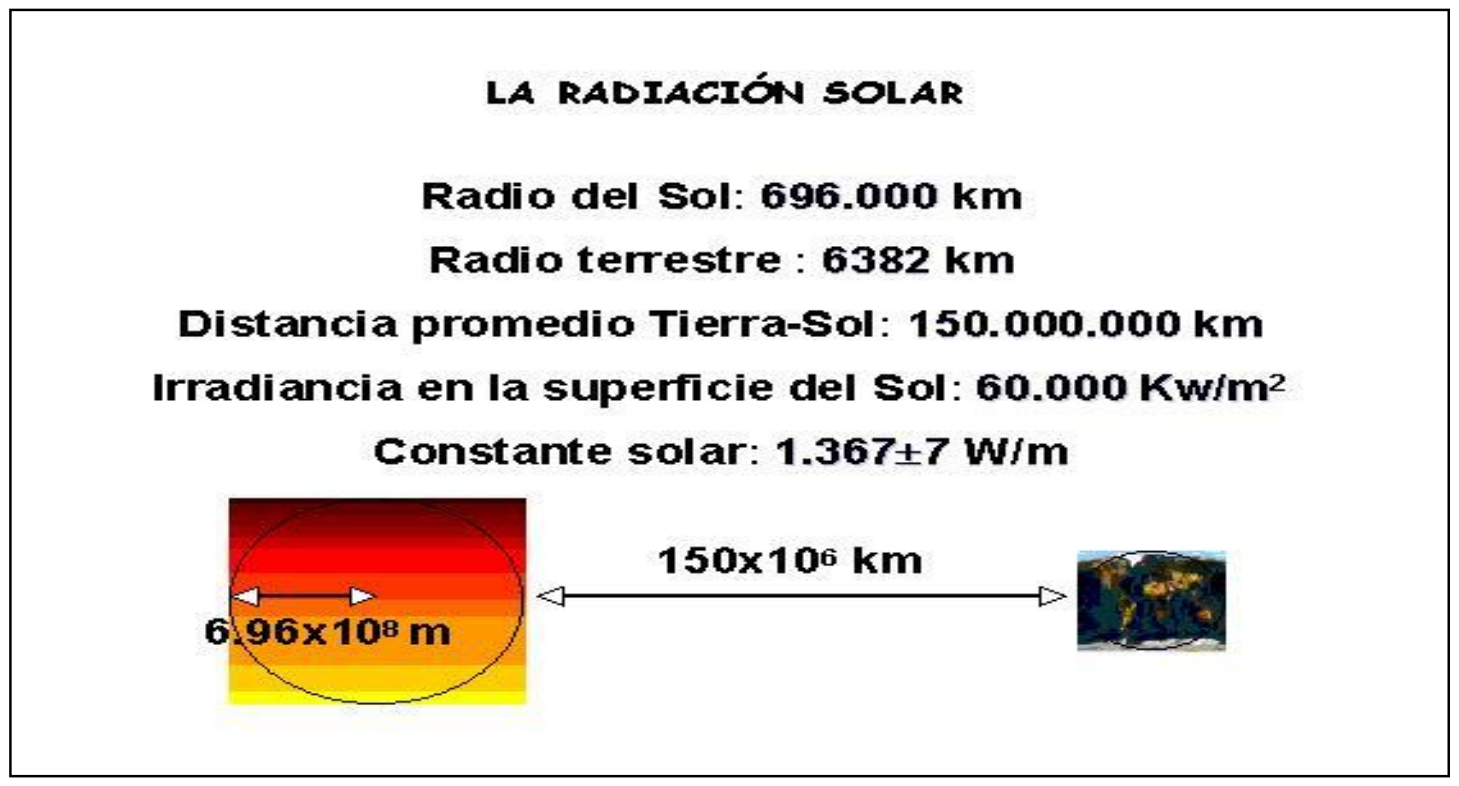

Fig. 3 Información básica sobre la radiación solar.

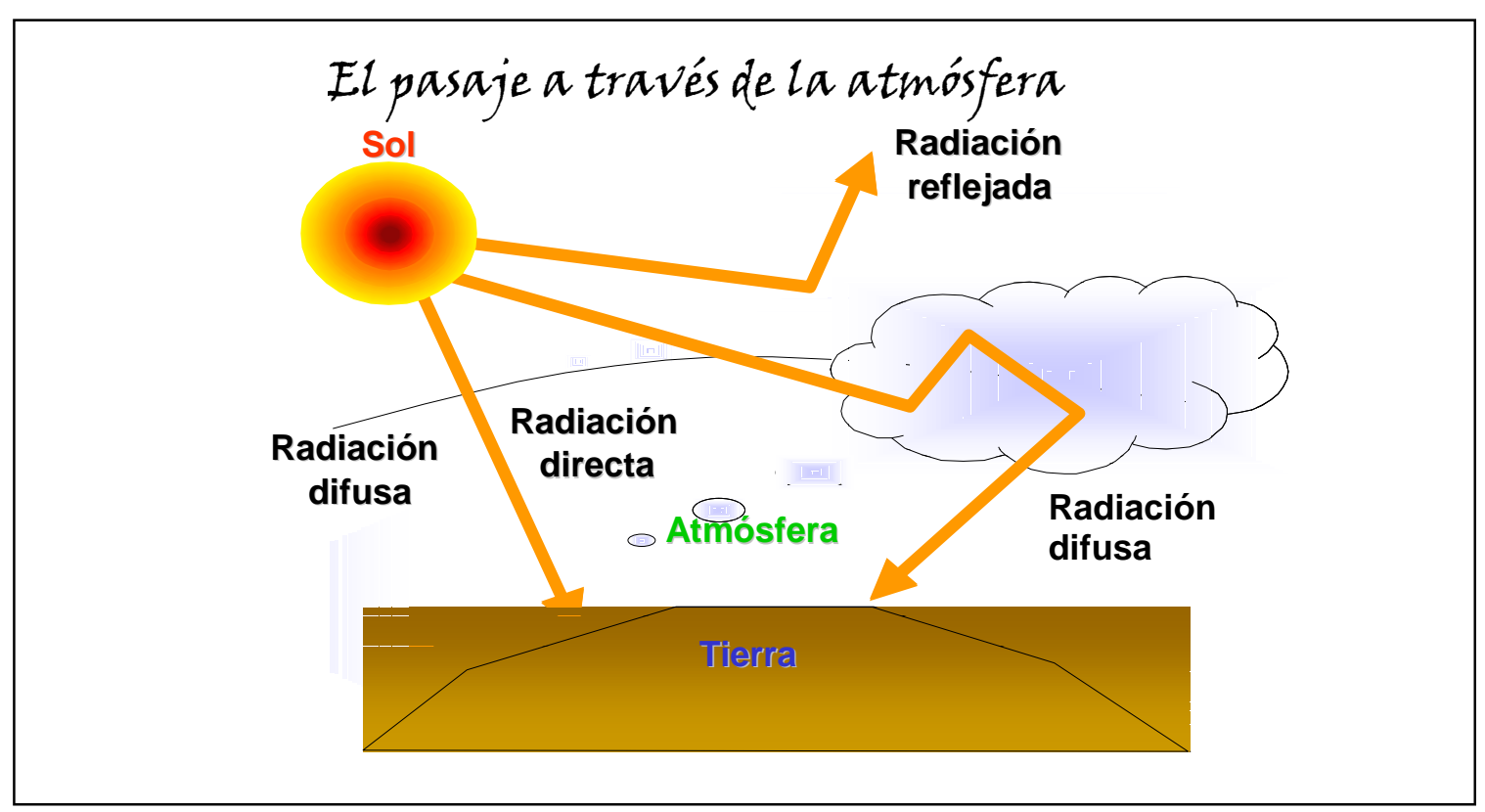

Fig. 4 Pasaje de la radiación solar a través de la atmósfera.

La atenuación depende de la longitud de onda, y los comportamientos de la radiación UV y visible son distintos. De la radiación global que llega a la superficie terrestre no más del $7 \%$ está en el rango UV-A. Para la purificación de agua, como veremos, esta pequeña fracción es muy importante, y la información disponible sobre cuánto incide en un determinado sitio es escasa en Iberoamérica. En la Argentina existe una Red de Monitoreo de la Radiación UV, con cuatro estaciones de muestreo que mide la radiación en cuatro bandas: 305,320 , 340 y $380 \mathrm{~nm}$. 
Hemos construido procedimientos para estimar la disponibilidad de la radiación en todo el espectro UV-A a partir de estas mediciones, y también procedimientos para estimar la irradiancia UV-A a partir de información sobre radiación global, que es más abundante.

\section{EL USO DE LA RADIACIÓN SOLAR PARA DESINFECTAR Y DESCONTAMINAR AGUAS}

A continuación podemos notar las diversas formas de uso directo de la radiación solar para desinfectar y descontaminar aguas.

\section{El uso de la radiación solar para tratar aguas}

- Fotooxidación heterogénea (FH).Aprovecha sólo el UV-A, y sirve para destruir totalmente compuestos orgánicos, para desinfectar aguas, y para la remoción de metales.
- Fotosensibilización heterogénea.Aprovecha la radiación visible, y sirve para desinfectar aguas.

- Otras Tecnologías Avanzadas de Oxidación Solar (Foto-Fenton, UV/peróxido, etc): Similares a FH, trabajan en medios homogéneos.

- Calentamiento solar del agua (destilación, pasteurización, SODIS) sirve para desinfectar aguas. FUENTE: Eliminación de Contaminantes por Fotocatálisis Heterogénea, Eds. CIEMAT, Madrid (2004).

La Fotooxidación Heterogénea (FH), usa como fotocatalizador, dióxido de titanio. Este semiconductor de banda ancha, bajo iluminación, genera especies fuertemente oxidantes y reductoras que median en la reacción entre el oxígeno y el contaminante, acelerándola notablemente. La Figura 5 muestra un esquema del proceso.

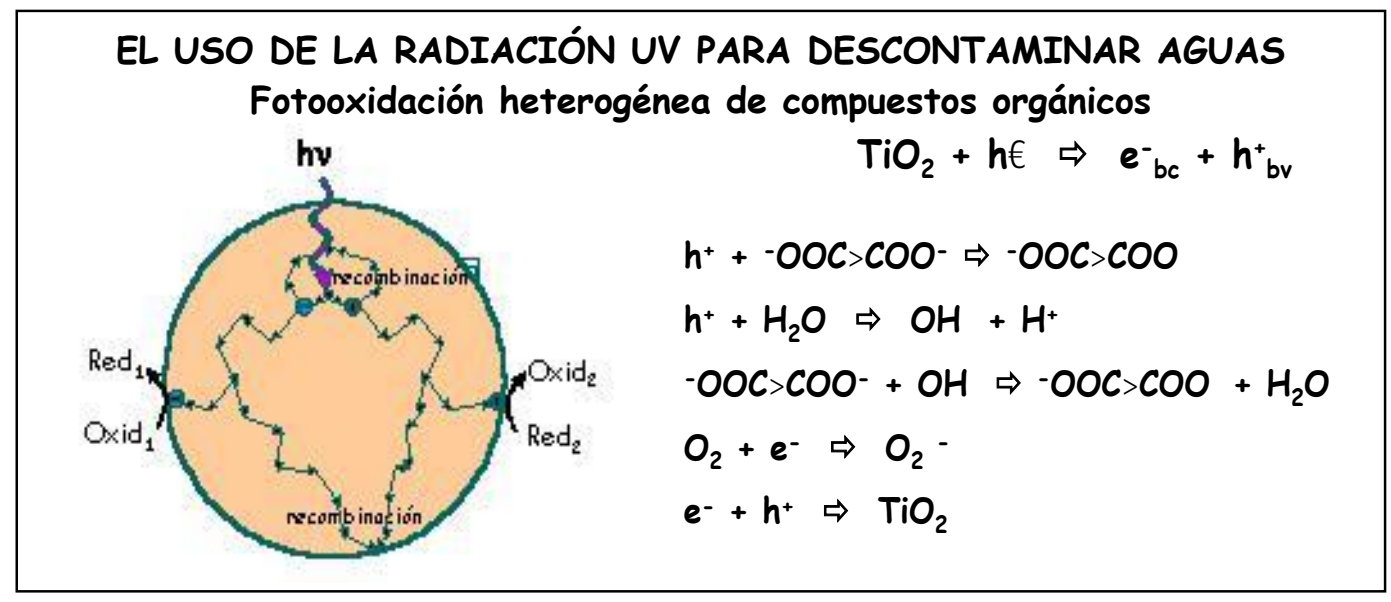

Fig. 5 Esquema del proceso de generación de radicales mediante la fotocatálisis heterogénea.

Un aspecto crucial de este método para destruir contaminantes es la necesidad que dicho contaminante se ponga en íntimo contacto con el fotocatalizador sólido. Los contaminantes orgánicos forman en muchos casos complejos superficiales con los átomos de titanio del sólido, y esos complejos pueden caracterizarse estructuralmente, mediante espectroscopía de infrarrojo. La Figura 6 muestra cómo la señal de infrarrojo va despareciendo a medida que el compuesto (en este caso ácido oxálico) es destruido por irradiación UV-A. 


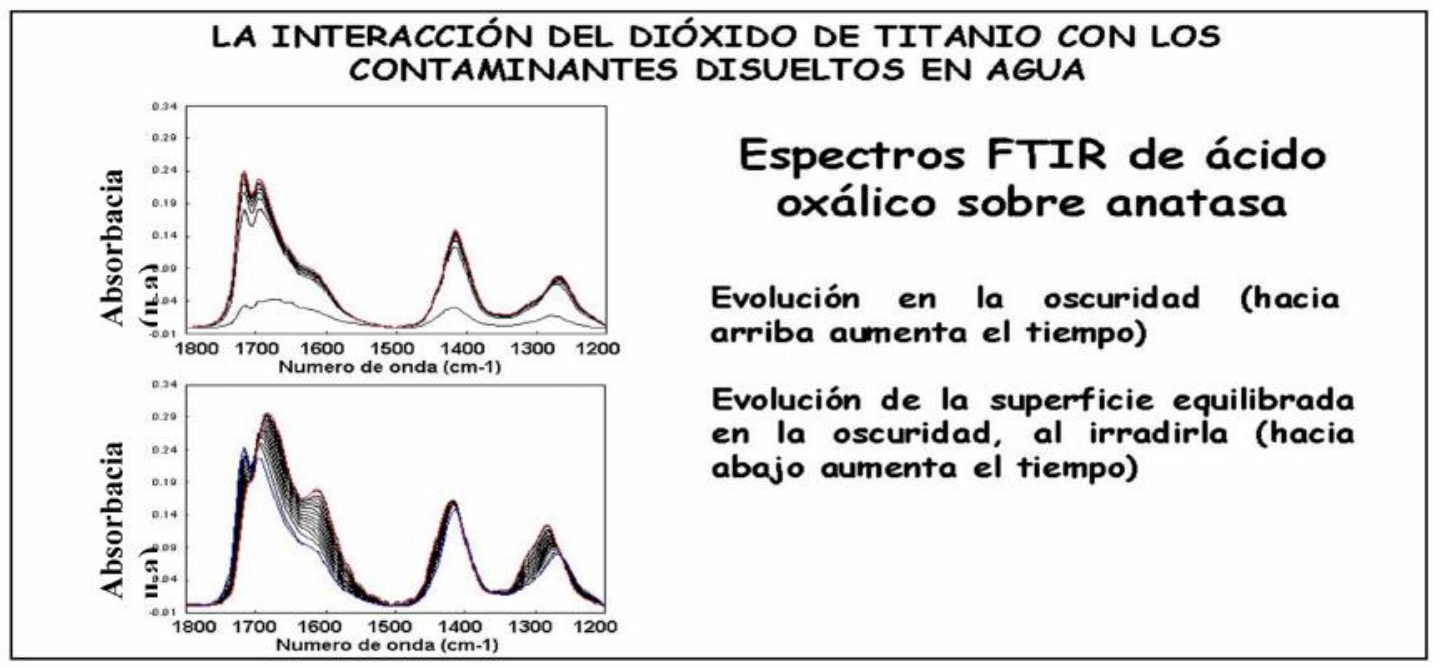

Fig. 6 Espectros infrarrojos de la inteacción de dióxido de titanio con contaminantes disueltos en agua.

El uso de FH requiere de catalizadores adecuados. Últimamente hemos implementado un método de síntesis de dióxido de titanio mesoporoso, que contiene poros, en los cuales, el contaminante pueda retenerse para su posterior destrucción fotolítica. El esquema se muestra en la Figura 7, y el material ha dado resultados prometedores.

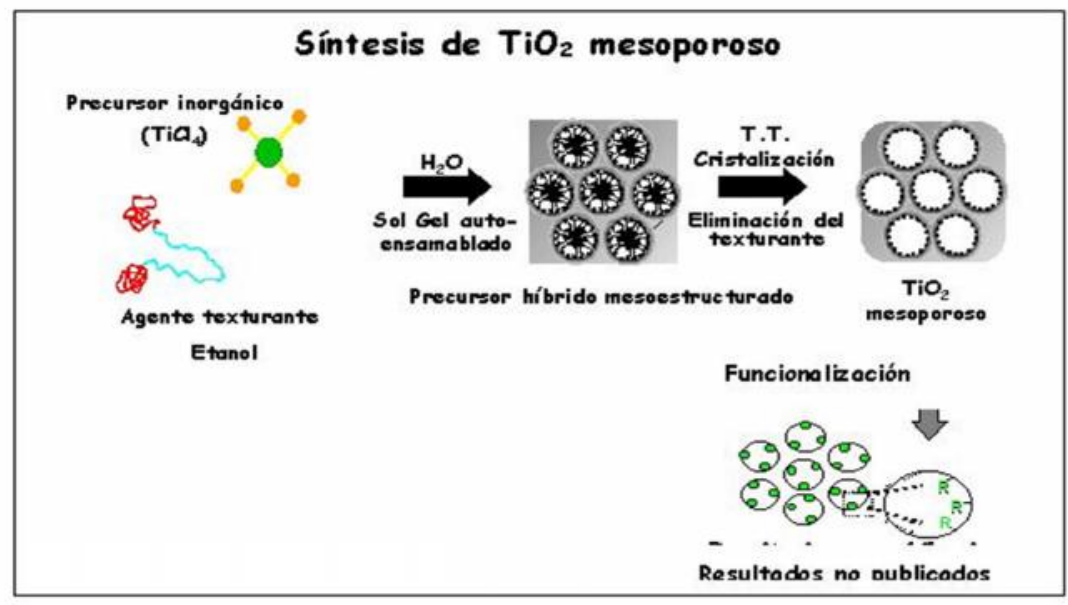

Fig.7 Sintesis del dióxido de titanio mesoporoso.

La FH destruye totalmente la materia orgánica. La contaminación metálica no puede destruirse totalmente, pero la FH puede ayudar a transformar los iones metálicos disueltos facilitando su remoción. Así por ejemplo, se puede buscar reducir el cromato a óxido de cromo (III), o el ion mercúrico a mercurio metálico. También se puede buscar oxidar arsénico (III) a arsénico (V).

La remoción de metales aprovechando la luz solar puede basarse en la $\mathrm{FH}$, pero también es posible su uso más directo. La Remoción de Arsénico por
Oxidación Solar (RAOS) se basa en la oxidación del $\mathrm{Fe}^{2+}$ presente en el agua (preexistente, o agregado a propósito), por el oxígeno disuelto en presencia de jugo de limón, que provee ácido cítrico (ver Figura 8). En la oxidación se forma un flóculo de óxido férrico que incorpora el arsénico. La oxidación es un fenómeno que involucra especies muy reactivas, las que permiten oxidar al As(III) en caso de estar el arsénico presente. Un método similar, que usa limaduras de hierro o alambre de enfardar bajo la luz solar, permite la formación del óxido de hierro en la superficie del 
hierro, facilitando su posterior remoción. Hemos

Tucumán, con resultados promisorios. realizado pruebas de campo en la Provincia de

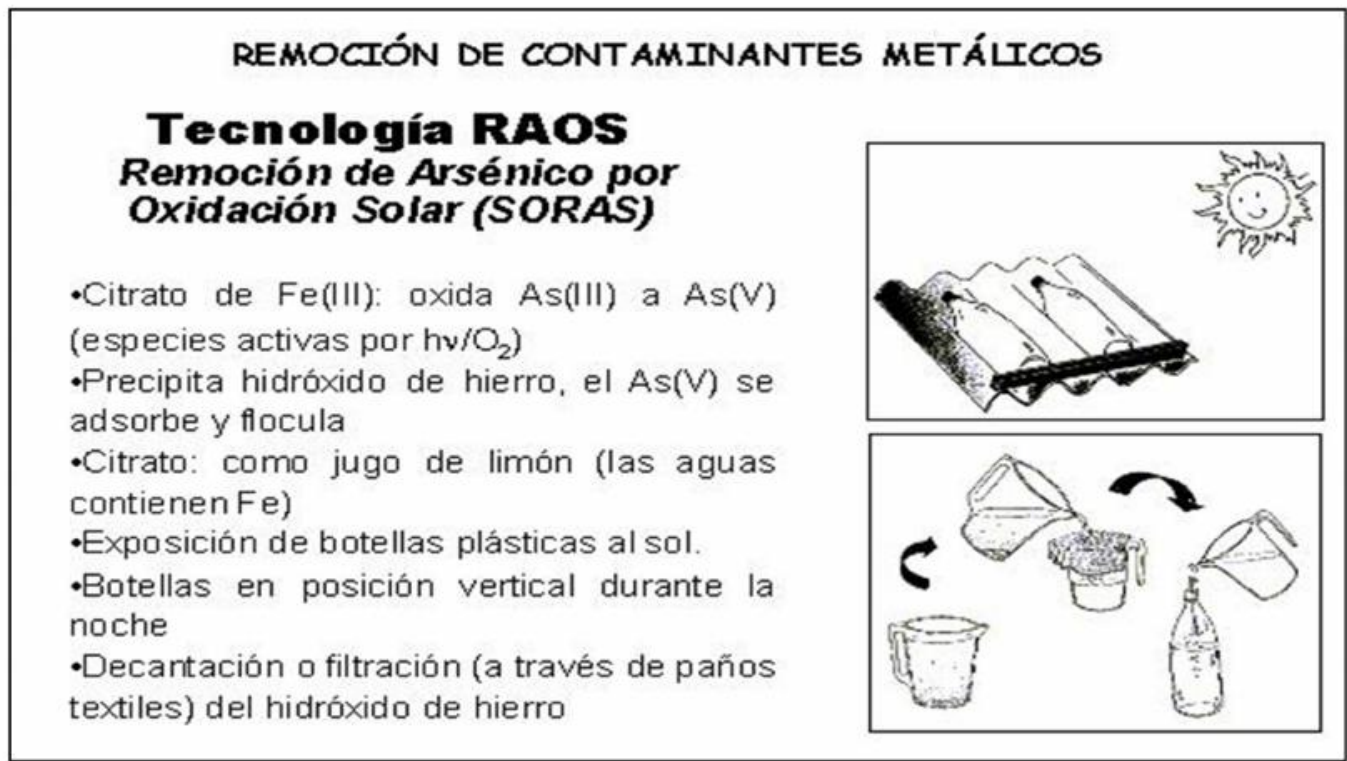

Fig. 8 Esquema del proceso de remoción de arsénico por oxidación solar.

\section{LAS PRUEBAS EN ARGENTINA CON EL REACTOR SOLWATER PARA LA DESINFECCIÓN DE AGUAS}

Por su capacidad para atacar la materia orgánica, la FH es también apta para inactivar bacterias. El reactor SOLWATER (Figura 9) se basa en el uso de la radiación UV solar, para la destrucción por FH de las bacterias y otros microorganismos patógenos que pueda contener el agua que consumen pobladores en regiones aisladas, sin servicios de red. Adicionalmente, usa la luz visible, en un proceso llamado Fotosensibilización Heterogénea. Este proceso usa complejos de rutenio (II) para producir oxígeno singlete, un agente eficaz para atacar los microorganismos (ver Figura 10). El agua a purificar circula por tubos, dos de los cuales contienen el fotocatalizador, mientras que los otros dos contienen el fotosensibilizador.

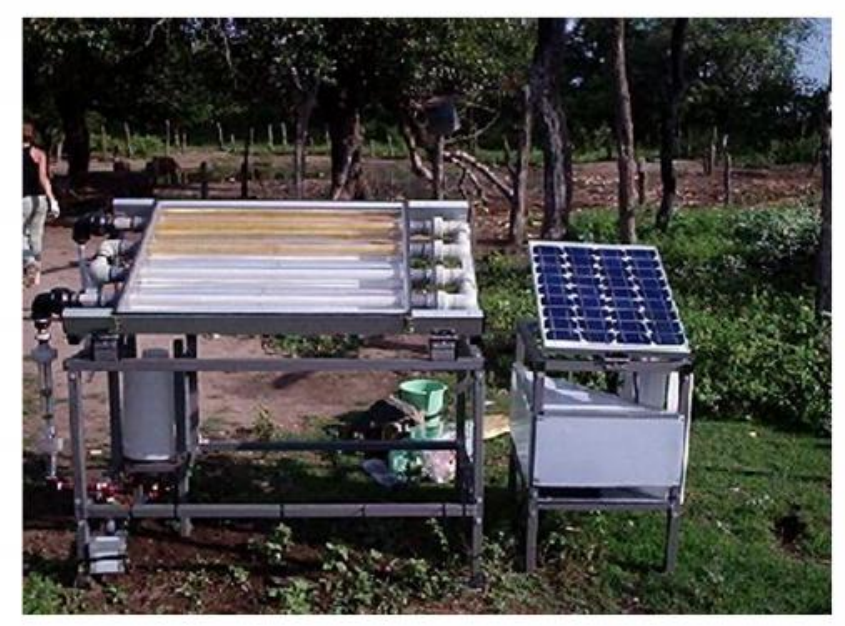

Fig. 9 Reactor SOLWATER. 


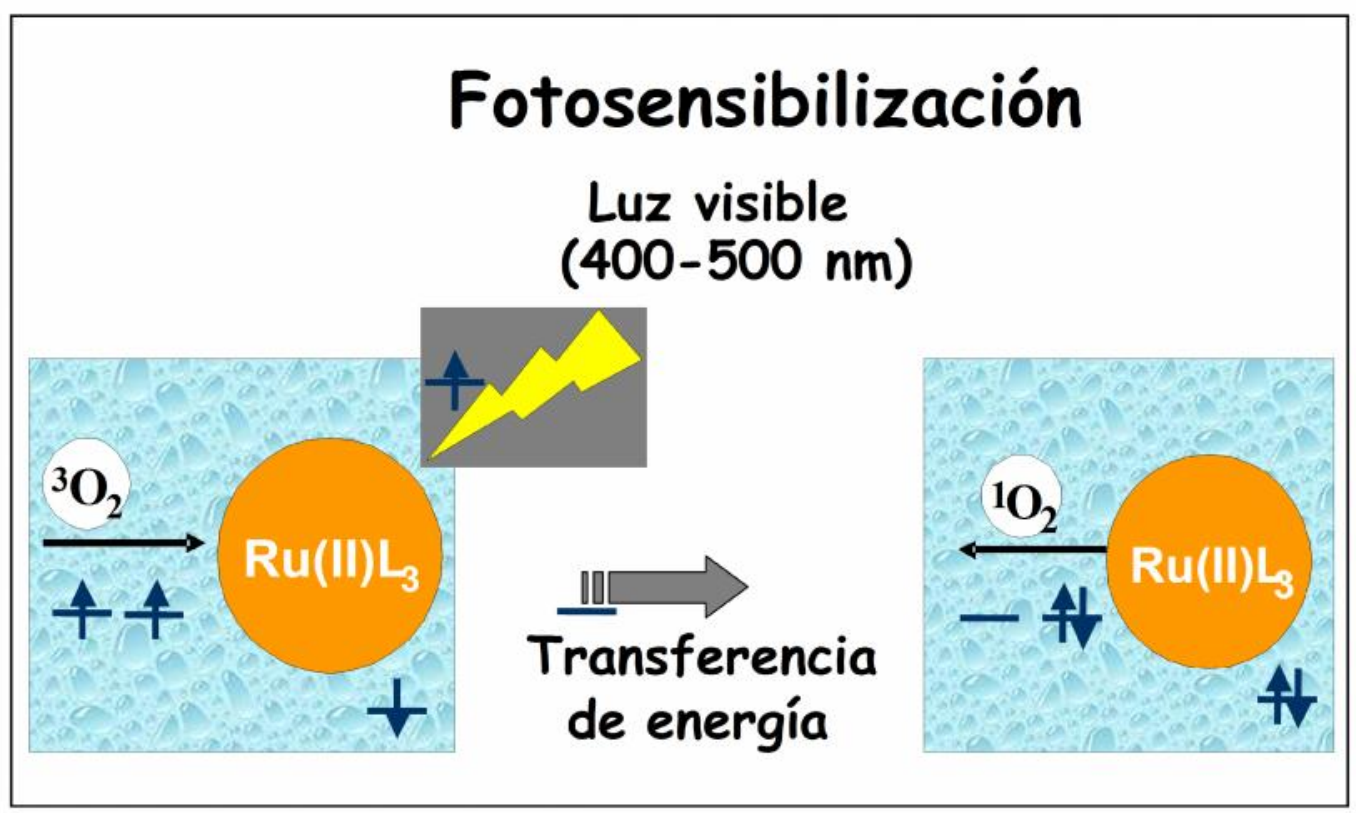

Fig.10 Proceso de producción del oxigeno singulete.

La Figura 11 muestra como ejemplo los resultados de destrucción de coliformes fecales encontrados en el agua de pozo de Los Pereyra, en la Provincia de Tucumán. Se comparan los niveles iniciales con los encontrados después de tres y seis horas de irradiación, alrededor del mediodía solar. Otros microorganismos se comportaron de manera análoga.

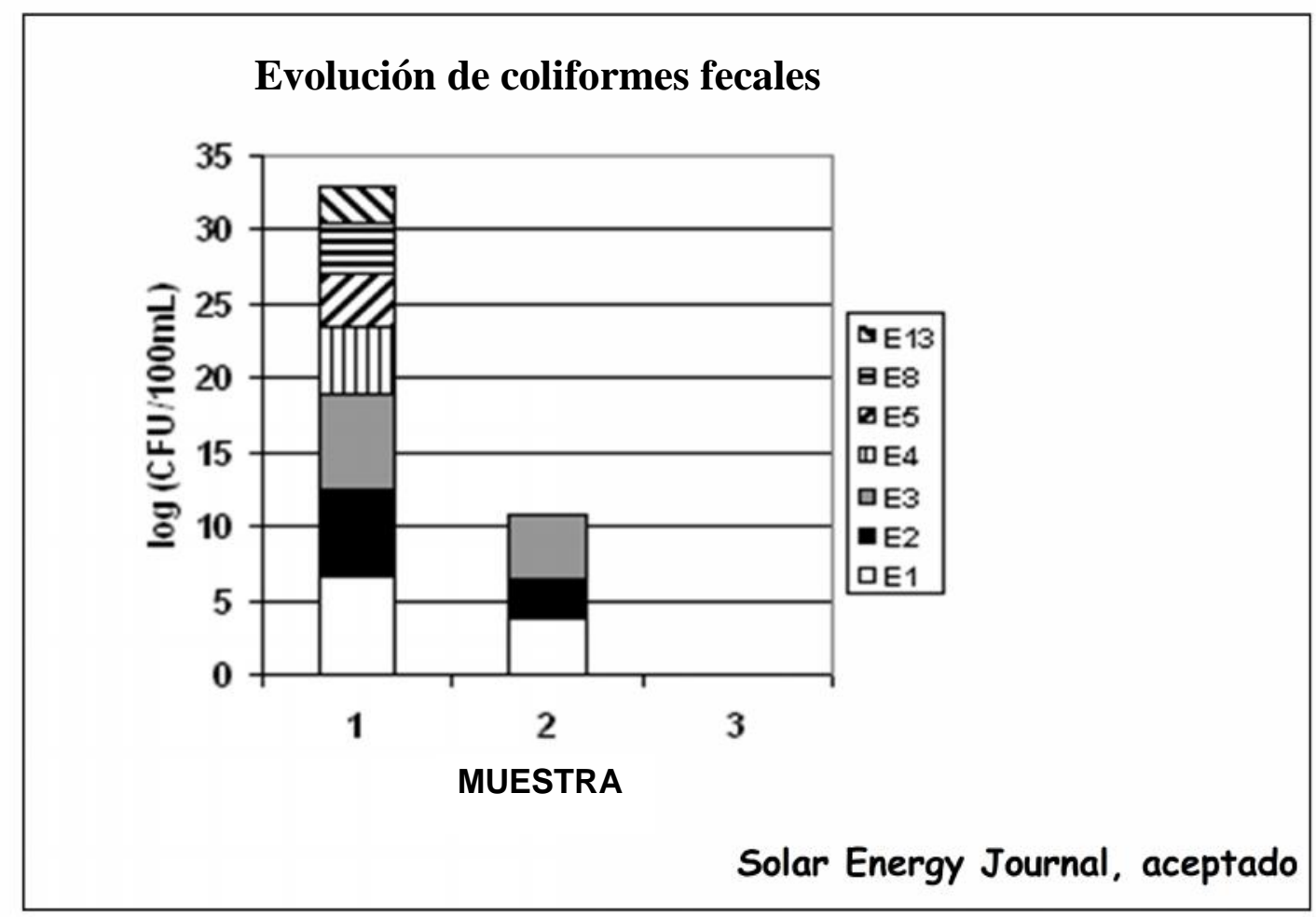

Fig. 11 Resultados de destrucción de coliformes fecales encontrados en el agua de pozo de Los Pereyra. 


\section{CONCLUSIONES}

La radiación solar, abundante en nuestra región, puede usarse para descontaminar y desinfectar agua, mediante tecnologías que, si bien se basan en conceptos de avanzada, pueden implementarse de forma económica. Todos los estudios y resultados mostrados en este trabajo están en diversas etapas de transferencia al medio. La transferencia es una etapa adicional, y difícil, cuya importancia no puede minimizarse.

\section{AGRADECIMIENTOS}

Este trabajo fue financiado por CNEA, UNSAM, UNT, Unión Europea, OEA, ANPCyT, CONICET, CIUNT, CICPBA y CyTED.

Correspondencia: miblesa@cnea.gov.ar 